\title{
Prediction of Skid Resistance Value of Glass Fiber-Reinforced Tiling Materials
}

\author{
Sadik Alper Yildizel, ${ }^{1}$ Yesim Tuskan, ${ }^{2}$ and Gökhan Kaplan ${ }^{3}$ \\ ${ }^{1}$ Faculty of Engineering, Department of Civil Engineering, Karamanoglu MehmetBey University, Karaman, Turkey \\ ${ }^{2}$ Faculty of Engineering, Department of Civil Engineering, Manisa Celal Bayar University, Manisa, Turkey \\ ${ }^{3}$ Faculty of Engineering, Department of Civil Engineering, Kastamonu University, Kastamonu, Turkey \\ Correspondence should be addressed to Sadik Alper Yildizel; sayildizel@kmu.edu.tr
}

Received 3 July 2017; Revised 17 October 2017; Accepted 29 October 2017; Published 19 December 2017

Academic Editor: Cumaraswamy Vipulanandan

Copyright ( 92017 Sadik Alper Yildizel et al. This is an open access article distributed under the Creative Commons Attribution License, which permits unrestricted use, distribution, and reproduction in any medium, provided the original work is properly cited.

\begin{abstract}
This research focuses on the use of adaptive artificial neural network system for evaluating the skid resistance value (British Pendulum Number; BPN) of the glass fiber-reinforced tiling materials. During the creation of the neural model, four main factors were considered: fiber, calcium carbonate content, sand blasting, and polishing properties of the specimens. The model was trained, tested, and compared with the on-site test results. As per the comparison of the outcomes of the study, the analysis and on-site test results showed that there is a great potential for the prediction of BPN of glass fiber-reinforced tiling materials by using developed neural system.
\end{abstract}

\section{Introduction}

Many researches have been focused on the skid and slip resistance properties of the construction materials in order to lessen accident rates in developed countries. These countries, especially the USA, where severe environmental conditions occur, have made huge expenses incurred by slipping accidents. The cost of the accidents in the USA is 37.3 and 64.41 billion dollars in 1985 and 1994, respectively [1]. Moreover, the estimated cost of the year 2020 is approximately 85 billion dollars [2]. Two hundred thousand people are injured annually due to the fallingcaused accidents, and among them, close to one percent lose their lives [3].

Nowadays, studies have been conducted on three main objectives: (i) human foot wear and their standards, (ii) construction materials and their standards, and (iii) the environment [1]. Generally, in the construction materials industry, all test equipment are produced and operated based on rubber friction. Those test tools basically consist of a vertical load, a projected speed, and a friction measurement wheel. On contrary to their simple structure, testing via this equipment sometimes becomes complex and expensive, if large-size construction materials are planned for testing. Besides, the test results vary depending on the dynamic factors such as temperature, test speed, rubber quality and aging, and even material curviness [4]. These factors directly affect the skid resistance, and it is very problematic to control them due to their nature.

Many approaches have been developed to determine the skid resistance value of the materials. Some of them depend on 2-dimensional or 3-dimensional data of the material surface with the aid of laser sensors [5-7]. Depolarizationbased methods had been studied but not improved since optical properties of the materials did not reflect the interaction between the material and the impact source $[8,9]$. Prediction through the surface properties of the material and relevant studies in the literature can include some regression models, fuzzy logic, and artificial neural networks [10-12].

Even though there is wide-ranging knowledge on the interaction between the construction material and the skid origin in recent years, a safe and stable method has not been developed yet. The most preferred and accredited 
TABLE 1: Alkali-resistant glass fiber properties.

\begin{tabular}{lr}
\hline Property & Fiber values \\
\hline Softening point & $850^{\circ} \mathrm{C}$ \\
Chemical resistance & High \\
Elasticity modulus & $72,000 \mathrm{Mpa}$ \\
Tensile strength & $1700 \mathrm{MPa}$ \\
Dry density & $2.65 \mathrm{~g} / \mathrm{cm}^{3}$ \\
Electrical conductivity & Very low \\
\hline
\end{tabular}

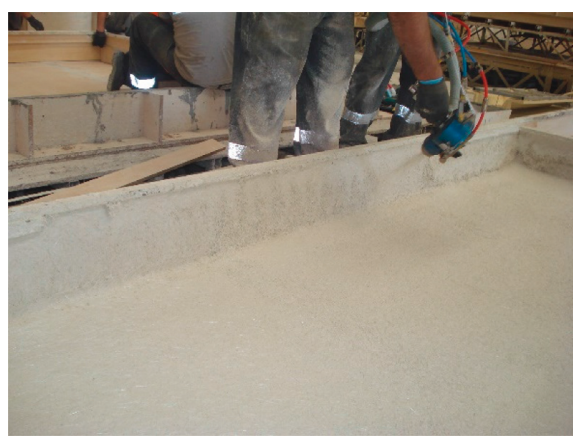

FIGURE 1: Spraying process.

TABLe 2: The chemical and physical properties of CEM I $52.5 \mathrm{R}$ cement.

\begin{tabular}{|c|c|c|c|}
\hline \multicolumn{2}{|c|}{ Chemical properties (\%) } & \multicolumn{2}{|c|}{ Physical and mechanical properties } \\
\hline $\mathrm{SiO}_{2}$ & 21.6 & Specific weight & 3.06 \\
\hline $\mathrm{Al}_{2} \mathrm{O}_{3}$ & 4.05 & Specific surface $\left(\mathrm{cm}^{2} / \mathrm{g}\right)$ & 4600 \\
\hline $\mathrm{Fe}_{2} \mathrm{O}_{3}$ & 0.26 & Whiteness (\%) & 85.5 \\
\hline $\mathrm{CaO}$ & 65.7 & Initial setting $(\mathrm{min})$ & 100 \\
\hline $\mathrm{MgO}$ & 1.30 & Final setting $(\mathrm{min}) \mathrm{s}$ & 130 \\
\hline $\mathrm{Na}_{2} \mathrm{O}$ & 0.30 & Water used for consistency (\%) & 30 \\
\hline $\mathrm{K}_{2} \mathrm{O}$ & 0.35 & Volume constancy (mm) & 1.0 \\
\hline $\mathrm{SO}_{3}$ & 3.30 & Remnants obtained using 0.045 sieve (\%) & 1.0 \\
\hline Free $\mathrm{CaO}$ & 1.60 & Remnants obtained using 0.090 sieve (\%) & 0.1 \\
\hline Chloride $(\mathrm{Cl})$ & 0.01 & Compressive strength for 2 days (MPa) & 37.0 \\
\hline Insoluble & 0.18 & Compressive strength for 7 days ( $\mathrm{MPa})$ & 50.0 \\
\hline Loss on ignition & 3.20 & Compressive strength for 28 days (MPa) & 60.0 \\
\hline
\end{tabular}

material to produce test equipment is rubber. During the skid resistance tests, it loses its internal dumping energy, and this confirms that the main factor affecting the test result is the surface of the material $[13,14]$.

Artificial neural networks (ANNs) are characteristic methods to model the comportment of the brain functions and human nervous system [15]. ANN is an information system that aims at providing capabilities such as the human brain resembles systems of learning, association, classification, generalizing, estimation, and optimization [16]. The limitations of various numerical modelling techniques and fails of many mathematical models for highly nonlinear behaviour of soils are also considered to be complex, time-consuming, and not always practical for civil engineering approaches. In construction material and geotechnical engineering problems, as with many areas of civil engineering, ANN has been used widely with high accuracy to predict and model the resistance values [15-18].

There are some components of the system including activation function, learning algorithm, and architecture structure taken into consideration depending on the performance of an ANN. Generally, ANNs are divided into two major types: namely, feed-forward (FF) and recurrent (R). One of the most well-known FF-ANNs is the multilayer perception (MLP) neural network. An ANN architecture can be consisted of an input layer, an output layer, and one or more hidden layers [19]. Back-propagation (BP) networks learn from continuing existence, and its characterization gained wide application in civil engineering [20]. The accuracy of model prediction is influenced by number of hidden layers and their neurons in the BP network [19]. Determination of the optimal number of 


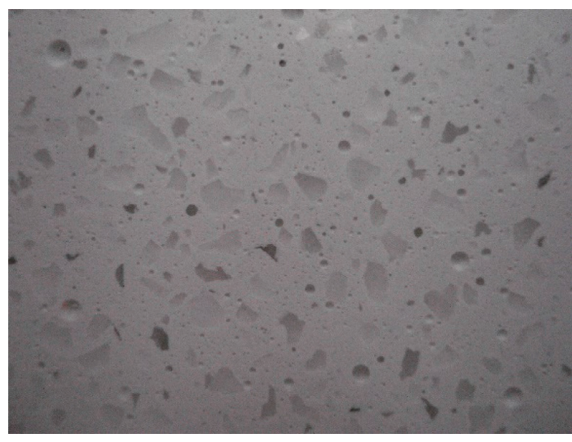

(a)

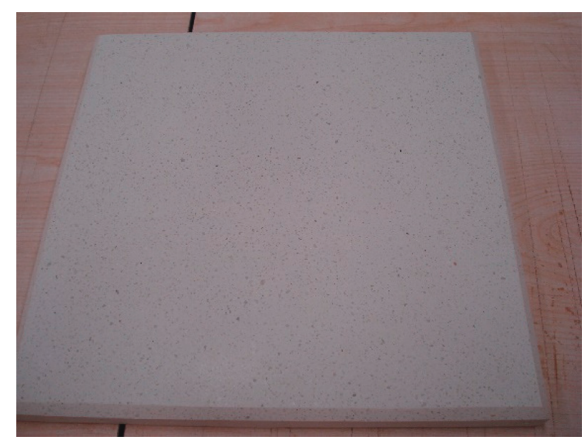

(b)

Figure 2: (a, b) Sand blasting applied specimens.

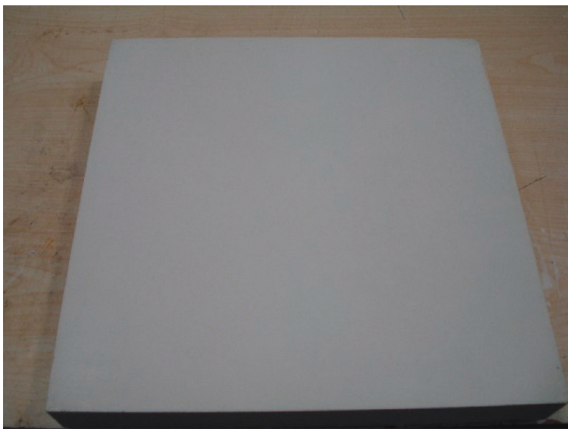

Figure 3: Polishing applied specimen.

TABLE 3: Details of the parameters used for the ANNs and MR models developed.

\begin{tabular}{|c|c|c|c|c|c|}
\hline Data type & Model parameters & Minimum value & Maximum value & Mean & Standard deviation \\
\hline \multirow{5}{*}{ ANN-1 input } & Calcium carbonate $3 \%$ & 0.00 & 10.00 & 2.81 & 3.72 \\
\hline & Calcium carbonate $5 \%$ & 0.00 & 7.50 & 1.94 & 2.74 \\
\hline & Calcium carbonate $10 \%$ & 0.00 & 10.00 & 1.94 & 3.55 \\
\hline & Fiber content & 0.00 & 2.50 & 1.87 & 0.63 \\
\hline & Sand blasting & 0.00 & 1.00 & 0.38 & 0.49 \\
\hline \multirow{5}{*}{ ANN-2 input } & Calcium carbonate $3 \%$ & 0.00 & 10.00 & 2.81 & 3.72 \\
\hline & Calcium carbonate $5 \%$ & 0.00 & 7.50 & 1.94 & 2.74 \\
\hline & Calcium carbonate $10 \%$ & 0.00 & 10.00 & 1.94 & 3.55 \\
\hline & Fiber content & 0.00 & 2.50 & 1.87 & 0.63 \\
\hline & Polishing & 0.00 & 1.00 & 0.63 & 0.49 \\
\hline Output & BPN & 56.00 & 73.00 & 64.30 & 3.45 \\
\hline
\end{tabular}

neurons in the hidden layer and the number of hidden layers depending on the complexity of the problem and the size of the database cannot be connected to a rule. The most accurate prediction is generally obtained with one hidden layer. However, the selection of sufficient number of neurons is presented under the feedback of these methods. The input variables are the main factors that affect the answers of this problem. And output variables corresponding to the number of neurons in the output layer are the expected answers to the problem. Neurons of the output layer communicate with the system of external environment by the configuration of output. The over rifting error on the training set can drive to a very small number; however, when the date is applied to the neural network, it becomes larger. This situation can be the cause of poor performance in machine learning $[18,21]$. Training MLP-ANN can be performed by different algorithms. As reported by several researchers, training algorithms are employed for the networks. At the end of the training phase of the ANN, the network produces outputs for the given inputs. These outputs are compared with the targets which are the simulation results.

Within the scope of this study, the British pendulum tester was preferred for the determination of the skid resistance value of the materials for posing experimental results and the comparison with the neural network analysis results. The prediction capability of the neural model has been studied. 


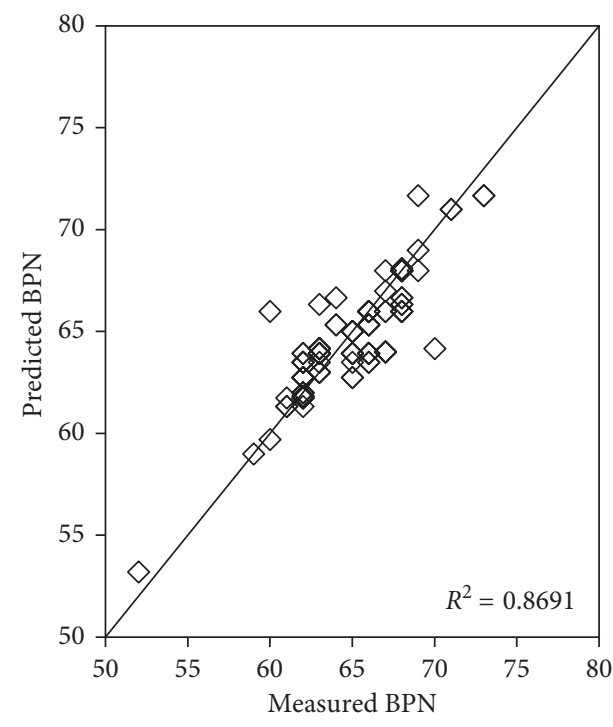

(a)

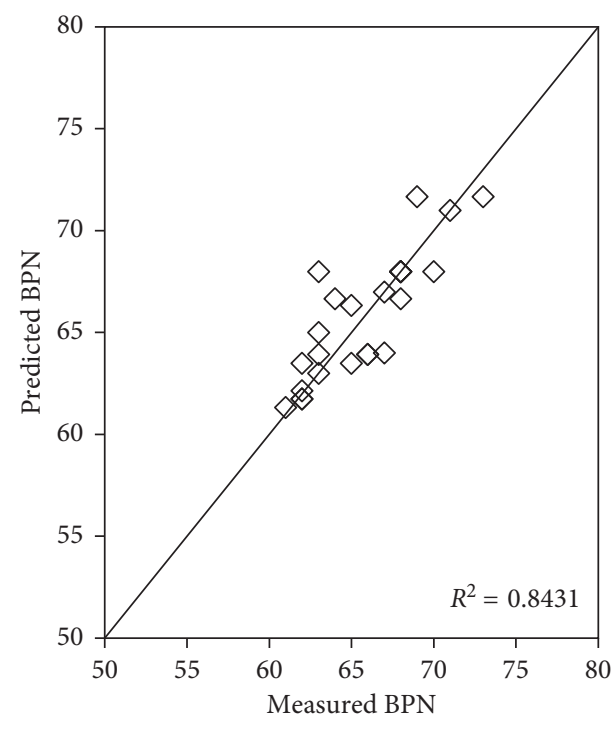

(b)

FIgURE 4: Comparison of the measured BPN values with the predicted BPN values from the ANN-1 model for (a) training and (b) testing samples under sand blasting condition.

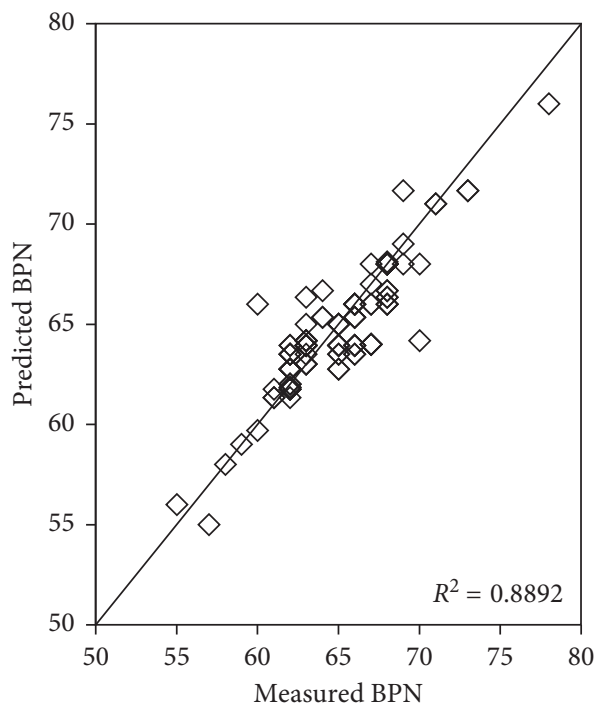

(a)

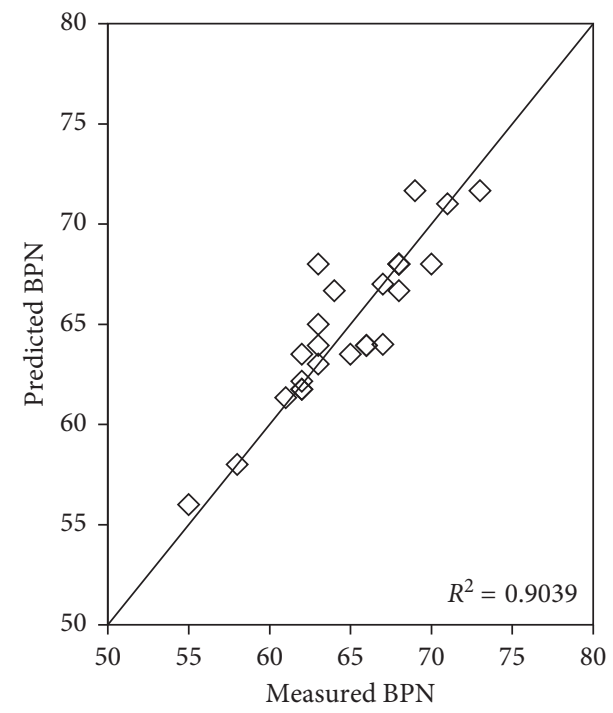

(b)

Figure 5: Comparison of the measured BPN values with the predicted BPN values from the ANN-2 model for (a) training and (b) testing samples under polishing condition.

\section{Glass Fibre-Reinforced Tiling Materials and Experimental Study}

Reinforcing a tile material by glass fibers is an efficient and stable method to enhance the strength and durability properties of tile materials [22]. Alkali-resistant glass fiber was used to increase concrete flooring materials' flexural capabilities. The physical and mechanical properties of the fibers are shown in Table 1.

Spray-cast methodology was applied for production line works (Figure 1). CEM I 52.5 R cement type was used for the mixture design of on-site applications. The chemical and the physical properties of the cement are presented in Table 2.

Alkali-resistant glass fibers were added to the mixes at the rates of $1 \%, 1.5 \%, 2 \%$, and $2.5 \%$ (maximum) in parallel with the relevant literature research [23-26]. As a cement replacement material, calcium carbonate was used at the rates of $5 \%, 7.5 \%, 2 \%$, and $10 \%$.

Following spraying process and the hardening of the tile material, polishing and sand blasting methods were applied to the surface of the materials (Figures 2 and 3). 


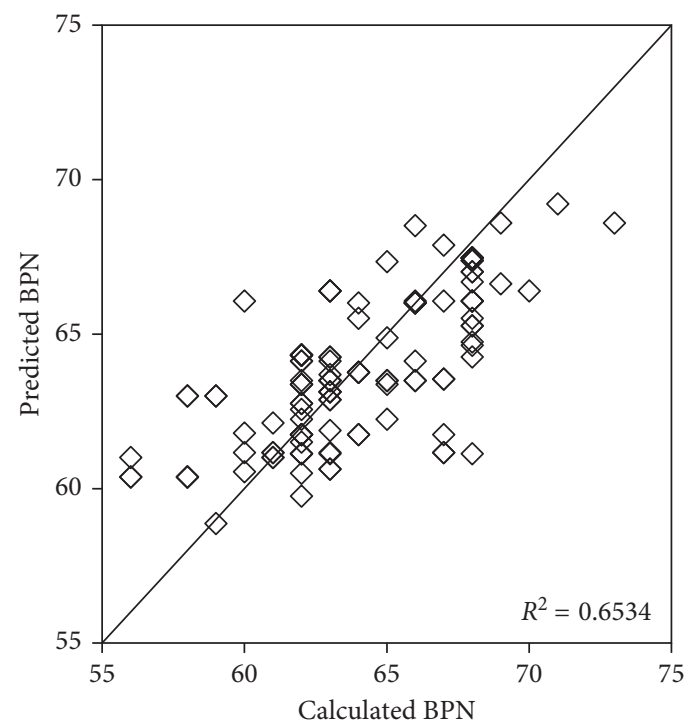

FIgURE 6: The comparison of the calculated BPN values with the predicted BPN values from the MR model for all samples.

TABle 4: Performance indices $\left(R^{2}\right.$, RMSE, MAE, and VAF) of the ANN and MR models.

\begin{tabular}{|c|c|c|c|c|c|}
\hline Model & Data & $R^{2}(\%)$ & RMSE & MAE & VAF \\
\hline \multirow{2}{*}{ ANN-1 } & Training set & 86.91 & 1.82 & 1.29 & 84.21 \\
\hline & Testing set & 84.31 & 1.25 & 1.56 & 85.84 \\
\hline \multirow{2}{*}{ ANN-2 } & Training set & 88.92 & 0.92 & 1.21 & 84.21 \\
\hline & Testing set & 90.39 & 1.05 & 0.96 & 85.84 \\
\hline MR & All data & 65.34 & 2.37 & 1.59 & 53.45 \\
\hline
\end{tabular}

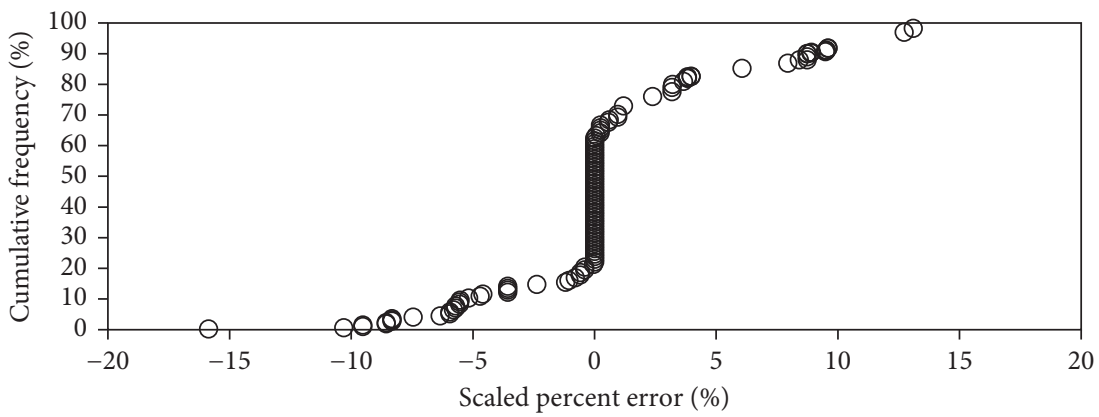

FIGURE 7: Scaled percent error of the BPN predicted from the ANN-1 model.

The British Pendulum Number of the all the specimens was all recorded with the use of the British pendulum tester.

\section{Artificial Neural Network Analysis}

A three-layered feed-forward MLP-ANN has been adopted for the skid resistance estimation. In this paper, the ANN-1 and ANN-2 are designed just to estimate the British Pendulum Number (BPN). In these models, the additives, namely, calcium carbonate $3 \%$, calcium carbonate (CC) $5 \%$, calcium carbonate $10 \%$, fiber content (FC), and sand blasting (SB), are the input parameters for ANN-1, and calcium carbonate $3 \%$, calcium carbonate (CC) $5 \%$, calcium carbonate $10 \%$, fiber content (FC), and polishing (P) are the input parameters for ANN-2. The observed BPN value was the only output parameter for both ANN models.

Data from several scenarios of similar problems have identified that, even by using just one hidden layer, any complex function in a network can be solved. Consequently, in this research, one hidden layer was chosen to make the ANN models. Data classification of ANN models was carried out as proposed: $80 \%$ of the data for training and $20 \%$ for testing [27-30]. In the model, log-sigmoid was utilized for transfer function while LM algorithm was employed to synthesize the ANN models. The details of the parameters considered during the BPN analysis in this study are given in Table 3. 


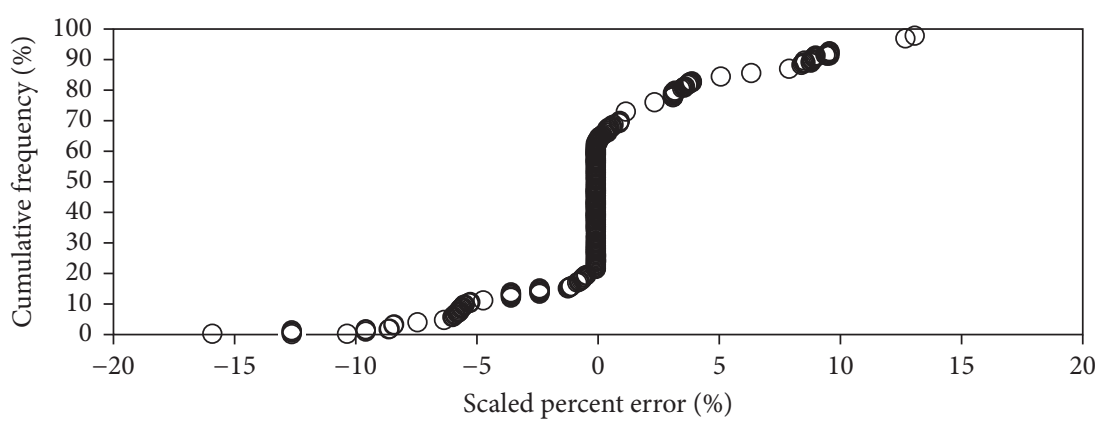

FIGURE 8: Scaled percent error of the BPN predicted from the ANN-2 model.

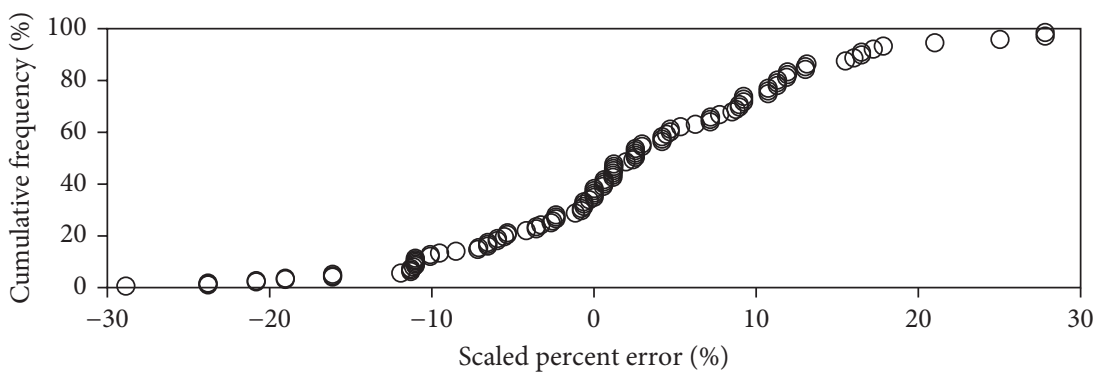

FIgURE 9: Scaled percent error of the BPN predicted from the MR model.

Based on different scenarios of additive assessment, polishing, and sand blasting, the BPN values modelled by MLP-ANN are shown in Figures 4 and 5. An overall good agreement between ANN models and experimental observation has been found.

$$
\begin{aligned}
\mathrm{BPN}= & 55.98+1.251 \times \mathrm{FC}+0.853 \times \mathrm{CC} 3 \%+1.002 \\
& \times \mathrm{CC} 5 \%+1.010 \times \mathrm{CC} 10 \%-1.749 \times \mathrm{P}, R=0.534 .
\end{aligned}
$$

It is noted from the results of the MR analysis that (1) has the $R$ value of 0.534 . It can be seen that $R$ value is not very high but shows good correlation with the results of very high $R^{2}$ values. It is observed that $\mathrm{ANN}$-predicted values are less scattered and are close to on-site measurements. These outcomes are in parallel with the results of the similar prediction studies $[29,30]$. Furthermore, in order to show the relationship between measured and predicted BPN values, BPN values predicted from (1) were compared with the BPN values calculated from the experimental observation, as shown in Figure 6 for all samples.

Following these calculations and analysis, performance of the ANN can be evaluated by four factors, namely, the determination coefficient $\left(R^{2}\right)$, variance account for (VAF), mean absolute error (MAE), and root mean square error (RMSE) in Table 4. In the case of determination coefficient, when the $R$ value is close to 1 , it can be concluded that the network can predict the data properly while in other performance factors, the minimum parameter is the best.

In addition to the performance indices, in order to gain an insight into the capabilities of the proposed correlations, a graph between the scaled percent error (SPE) (as given by (2)) and cumulative frequency is depicted in Figures 7-9, respectively, for the ANN-1, ANN-2, and MR models considering the data employed in this study as studied in similar literature researches [30-32].

$$
\mathrm{SPE}=\frac{\left(\mathrm{BPN}_{\mathrm{p}}-\mathrm{BPN}_{\mathrm{m}}\right)}{\left(\mathrm{BPN}_{\mathrm{m}}\right)_{\max }-\left(\mathrm{BPN}_{\mathrm{m}}\right)_{\min }},
$$

where $\mathrm{BPN}_{\mathrm{p}}$ and $\mathrm{BPN}_{\mathrm{m}}$ are the predicted and the measured British Pendulum Number $(\mathrm{BPN})$ and $\left(\mathrm{BPN}_{\mathrm{m}}\right)_{\max }$ and $\left(\mathrm{BPN}_{\mathrm{m}}\right)_{\mathrm{min}}$ are the maximum and the minimum measured $\mathrm{BPNs}$, respectively.

About $91 \%$ of the BPN value predicted from the ANN-2 model fall into $\pm 10 \%$ of the SPE, indicating a perfect estimate for the BPN value. About $71 \%$ of the BPN value predicted from the ANN- 2 model fall into $\pm 10 \%$ of the SPE, indicating a close estimate for the BPN value. These results indicate that ANN models developed were superior to the MR model in predicting the BPN value. It can be concluded that the ANN-2 model developed in this study can be used for the estimation of the BPN value and so for the determination of skid resistance and relevant measurements. The polishing property is found to be the most important input parameter followed by sand blasting based on the weight and the biases of the trained network.

\section{Results and Discussion}

In this study, the efficiency of the ANN and MR models to forecast the British Pendulum Number (BPN) has been investigated and compared. To achieve this, the BPN values were measured by changing the additive percentage, fiber ratio, polishing, and sand blasting conditions and utilized in 
the simulation of the ANN and MR models. The input parameters used in the ANN and MR models are four common additive percentages (CC 3\%, CC 5\%, CC 10\%, and fiber ratio) and two separate experiment conditions (polishing and sand blasting). The output parameter in both models is the measured British Pendulum Number (BPN).

The scatter plots of the calculated versus predicted BPN for the ANN models are shown in the previous section. Obviously, the plots approximate a straight line which confirms the high accuracy of the ANN-2 model for the prediction of the BPN. The $R^{2}$ values were 88.92 and 90.39 for training and testing data, respectively.

\section{Disclosure}

The authors certify that they have no affiliations with or involvement in any organization or entity with any financial interest (such as honoraria; educational grants; participation in speakers' bureaus; membership, employment, consultancies, stock ownership, or other equity interests; and expert testimony or patent-licensing arrangements) or nonfinancial interest (such as personal or professional relationships, affiliations, knowledge, or beliefs) in the subject matter or materials discussed in this paper.

\section{Conflicts of Interest}

The authors declare that they have no conflicts of interest.

\section{References}

[1] Z. Karaca, S. Gürcan, M. V. Gökçe, and O. Sivrikaya, "Assessment of the results of the pendulum friction tester (EN 14231) for natural building stones used as floor-coverings," Construction and Building Materials, vol. 47, pp. 1182-1187, 2013.

[2] F. Englander, T. J. Hodson, and R. A. Terregrossa, "Economic dimensions of slip and fall injuries," Journal of Forensic Sciences, vol. 41, no. 5, pp. 733-746, 1996.

[3] M. S. Redfern and B. Bidanda, "Slip resistance of the shoefloor interface under biomechanically-relevant conditions," Ergonomics, vol. 37, no. 3, pp. 511-524, 1994.

[4] A. Ueckermann, D. Wang, M. Oeser, and B. Steinauer, "Calculation of skid resistance from texture measurements," Journal of Traffic and Transportation Engineering, vol. 2, no. 1, pp. 3-16, 2015.

[5] X. Y. Mu, L. Li, N. Tang et al., "A laser-based system for highway pavement texture measurement," in Proceedings of the Conference on Intelligent Transportation Systems, Shanghai, China, November 2003.

[6] J. Kebrle and R. Walker, "Texture measurement and friction estimation using laser data acquisition and neural networks," in Proceedings of the 9th WSEAS Int Ernational Conference on Mathematical and Computational Methods in Science and Engineering, Trinidad and Tobago, November 2007.

[7] A. Cigada, F. Mancosu, S. Manzoni, and E. Zappa, "Laser triangulation device for in-line measurement of road texture at medium and high speed," Mechanical Systems and Signal Processing, vol. 24, no. 7, pp. 2225-2234, 2010.

[8] W.C. Spring III and W. L King, Light Depolarization as a Measure of Pavement Surface Texture: Final Report, Naval
Surface Weapons Center, Silver Spring, White Oak, MD, USA, 1981.

[9] J. C. Wambold, J. J. Henry, and R. R. Hegmon, "Evaluation of pavement surface texture significance and measurement techniques," Wear, vol. 83, no. 2, pp. 351-368, 1982.

[10] H. Zahouani, R. Vargiolu, and M. T. Do, "Characterization of microtexture related to wet road/tire friction," in Proceedings of the 4th International Symposium on Pavement Surface Characteristics SURF 2000, Nantes, France, May 2000.

[11] C. Schulze, "Ein geometrisch basiertes modell zur ableitung von reibwerten bei nasse aus der textur," Ph.D. thesis, RWTH Aachen University, Aachen, Germany, 2011.

[12] T. Ustuntas, "Prediction of skid resistance coefficient of cement concrete roads with fuzzy logic," Civil Eingineering and Environmental Systems, vol. 24, no. 3, pp. 233-246, 2007.

[13] K. A. Grosch, "The relation between the friction and viscoelastic properties of rubber," Proceedings of the Royal Society of London A, vol. 274, no. 1356, pp. 21-39, 1963.

[14] A. Schallamach, "The load dependence of rubber friction," Rubber Chemistry and Technology, vol. 26, no. 2, pp. 297-301, 1953.

[15] M. A. Shahin, M. B. Jaksa, and H. R. Maier, "Artificial neural network applications in geotechnical engineering," Australian Geomechanics, vol. 36, no. 1, pp. 49-62, 2001.

[16] S. Haykin and N. Network, Neural Networks: A Comprehensive Foundation, Vol. 2, Prentice Hall, p. 41, Upper Saddle River, NJ, USA, 2004.

[17] J. E. Sierra and M. Santos, "Modelling engineering systems using analytical and neural techniques: hybridization," Neurocomputing, vol. 271, pp. 70-83, 2017.

[18] X. Yang, A. H. Gandomi, S. Talatahari, and A. H. Alavi, "Artificial neural networks in geotechnical engineering: modeling and application issues, Chapter 10," in Metaheuristics in Water, Geotechnical and Transport Engineering, S. K. Das, ED., Elsevier, ISBN: 978-0-12-398296-4, pp. 231-270, London, UK, 2013.

[19] S. K. Das and P. K. Basudhar, "Utilization of self-organizing map and fuzzy clustering for site characterization using piezocone data," Computers and Geotechnics, vol. 36, no. 1-2, pp. 241-248, 2009.

[20] J. Shi, J. A. R. Ortigao, and J. Bai, "Modular neural networks for predicting settlements during tunneling," Journal of Geotechnical and Environmental Engineering, vol. 124, no. 5, pp. 389-395, 1998.

[21] A. T. Goh, "Seismic liquefaction potential assessed by neural networks," Journal of Geotechnical Engineering, vol. 120, no. 9, pp. 1467-1480, 1994.

[22] Z. Guo and R. E. Uhrig, "Use of artificial neural networks to analyze nuclear power plant performance," Nuclear Technology, vol. 99, no. 1, pp. 36-42, 1992.

[23] P. Purnell and J. Beddows, "Durability and simulated ageing of new matrix glass fibre reinforced concrete," Cement and Concrete Composites, vol. 27, no. 9-10, pp. 875-884, 2005.

[24] S. Naqvi, K. Mahmoud, and E. El-Salakawy, "Effect of axial load and steel fibers on the seismic behavior of lap-spliced glass fiber reinforced polymer-reinforced concrete rectangular columns," Engineering Structures, vol. 134, pp. 376-389, 2017.

[25] T. Simões, H. Costa, D. Dias-da-Costa, and E. Júlio, "Influence of fibres on the mechanical behaviour of fibre reinforced concrete matrixes," Construction and Building Materials, vol. 137, pp. 548-556, 2017.

[26] M. Mastali, A. Dalvand, and A. R. Sattarifard, "The impact resistance and mechanical properties of reinforced self- 
compacting concrete with recycled glass fibre reinforced polymers," Journal of Cleaner Production, vol. 124, pp. 312324, 2016.

[27] S. T. Tassew and A. S. Lubell, "Mechanical properties of glass fiber reinforced ceramic concrete," Construction and Building Materials, vol. 51, pp. 215-224, 2014.

[28] M. A. Shahin, H. R. Maier, and M. B. Jaksa, "Data division for developing neural networks applied to geotechnical engineering," Journal of Computing in Civil Engineering, vol. 18, no. 2, pp. 105-114, 2004.

[29] S. K. Das and P. K. Basudhar, "Undrained lateral load capacity of piles in clay using artificial neural network," Computers and Geotechnics, vol. 33, no. 8, pp. 454-459, 2006.

[30] M. A. Shahin, "Intelligent computing for modeling axial capacity of pile foundations," Canadian Geotechnical Journal, vol. 47, no. 2, pp. 230-243, 2010.

[31] A. Kanibir, R. Ulusay, and O. Aydan, Liquefaction-Induced Ground Deformations on a Lake Shore (Turkey) and Empirical Equations for their Prediction, IAEG, Paper 362, 2006.

[32] T. P. Thaker and K. S. Rao, Development of Statistical Correlations between Shear Wave Velocity and Penetration Resistance using MASW Technique, Pan-American CGS Geotechnical Conference, ON, Canada, 2011. 


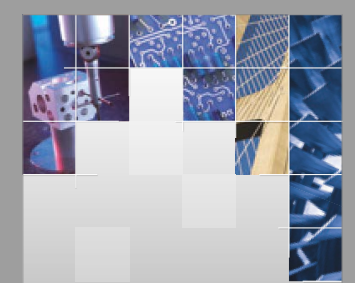

\section{Enfincering}
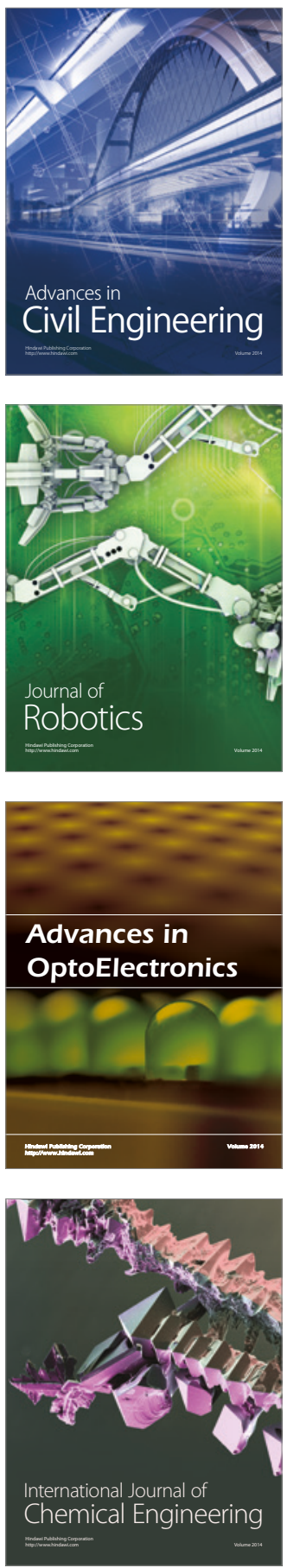

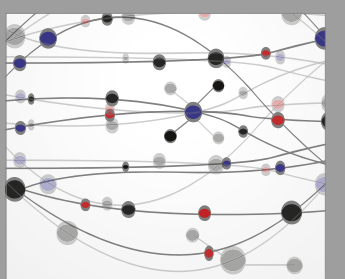

The Scientific World Journal

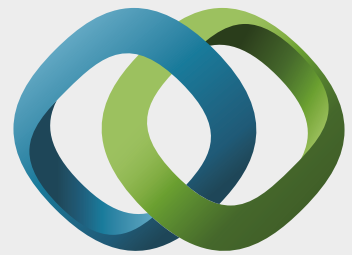

\section{Hindawi}

Submit your manuscripts at

https://www.hindawi.com
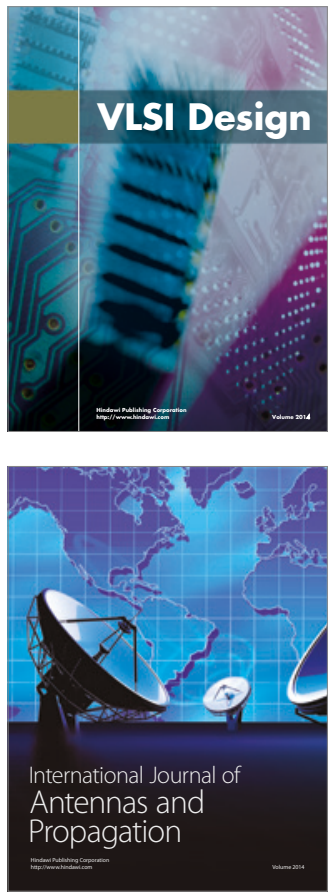

\section{Rotating}

Machinery
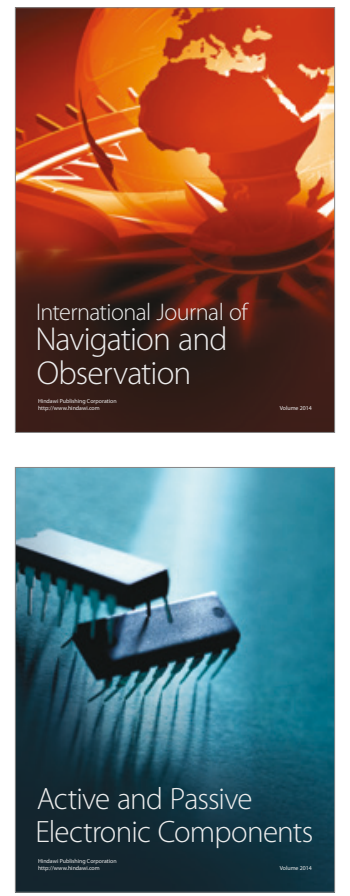
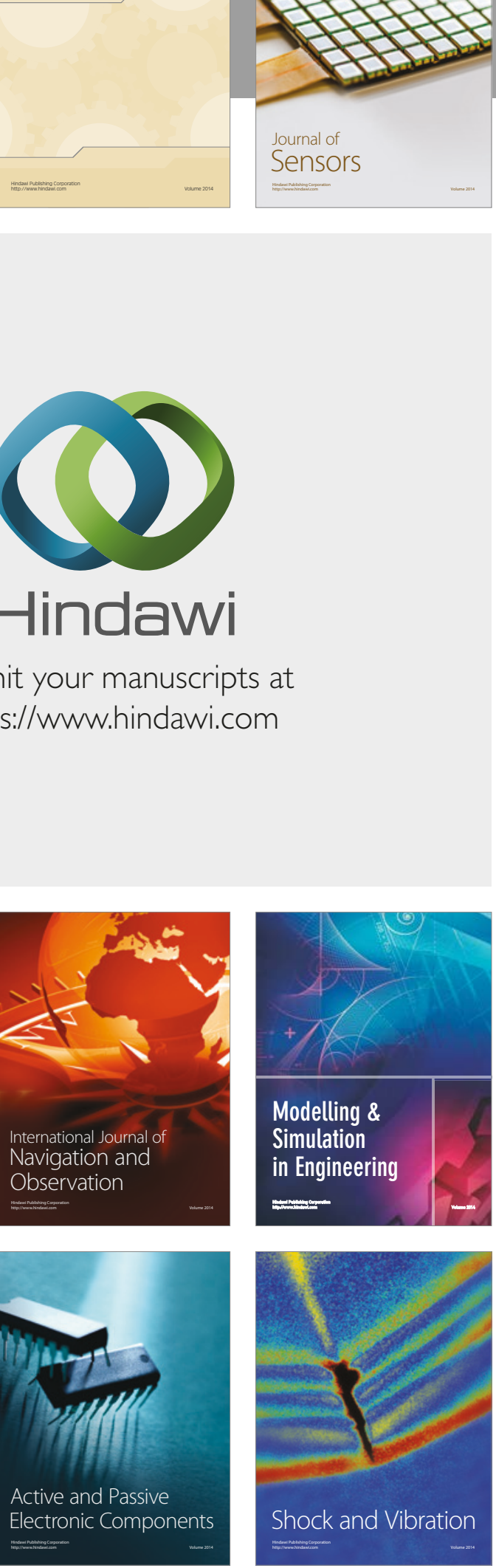
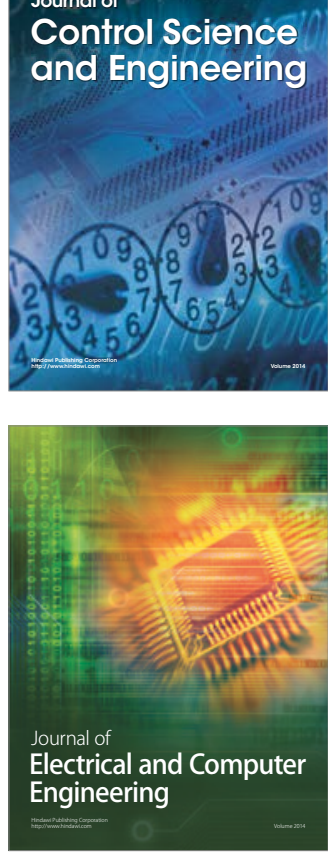

Distributed

Journal of

Control Science

and Engineering
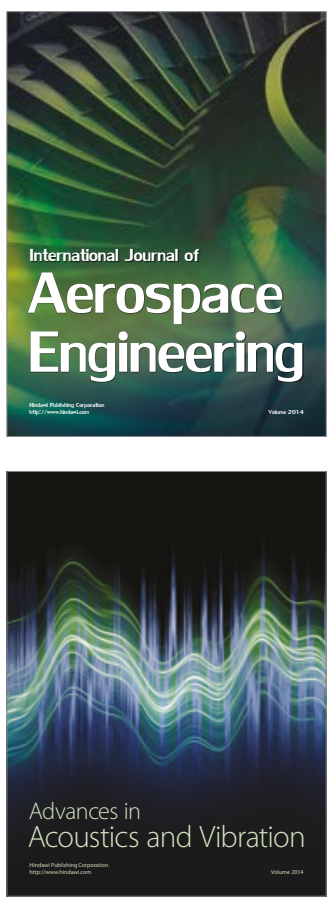

Sensor Networks 